This document is confidential and is proprietary to the American Chemical Society and its authors. Do not copy or disclose without written permission. If you have received this item in error, notify the sender and delete all copies.

\title{
Influence of three commercial graphene derivatives on the catalytic properties of a Lactobacillus plantarum alpha-L- rhamnosidase when used as immobilization matrices
}

\begin{tabular}{|r|l|}
\hline Journal: & ACS Applied Materials \& Interfaces \\
\hline Manuscript ID & am-2017-18844h.R3 \\
\hline Manuscript Type: & Article \\
\hline Date Submitted by the Author: & $30-$ Apr-2018 \\
\hline Complete List of Authors: & $\begin{array}{l}\text { Antón-Millán, Noemí; Universidad de Burgos - Campus San Amaro } \\
\text { Garcia-Tojal, Javier; Universidad de Burgos, } \\
\text { Marty-Roda, Marta; Universidad de Burgos } \\
\text { Garroni, Sebastiano; Unviersity of Burgos, ICCRAM } \\
\text { Cuesta-Lopez, Santiago; International Center for Advanced Materials and } \\
\text { Raw Materials of Castilla y Leon, Parque Tecnológico de León, Edificio de } \\
\text { Usos Múltiples } \\
\text { Tamayo-Ramos, Juan Antonio; Universidad de Burgos - Campus San } \\
\text { Amaro, ICCRAM }\end{array}$ \\
\hline
\end{tabular}


Influence of three commercial graphene derivatives on the catalytic properties of a Lactobacillus plantarum alpha-L-rhamnosidase when used as immobilization matrices

Noemí Antón-Millán ${ }^{1,2}$, Javier García-Tojal ${ }^{3}$, Marta Marty-Roda ${ }^{1,2}$, Sebastiano Garroni ${ }^{1,2}$, Santiago Cuesta-López ${ }^{1,2}$, Juan Antonio Tamayo-Ramos* ${ }^{* 1,2}$

1 International Research Centre in Critical Raw Materials-ICCRAM, University of Burgos, Plaza Misael Banuelos s/n, 09001 Burgos, Spain

2 Advanced Materials, Nuclear Technology and Applied Bio/Nanotechnology. Consolidated Research Unit UIC-154. Castilla y Leon. Spain. University of Burgos. Hospital del Rey s/n, 09001 Burgos, Spain.

3 Department of Chemistry, University of Burgos, Plaza Misael Bañuelos s/n., 09001 Burgos, Spain

*Contact e-mail: ja.tamayoramos@gmail.com

\section{Abstract}

The modification of carbon nanomaterials with biological molecules paves the way towards their use in biomedical and biotechnological applications, such as next generation biocatalytic processes, development of biosensors, implantable electronic devices, or drug delivery. In this study, different commercial graphene derivatives, namely, monolayer graphene oxide (GO), graphene oxide nanocolloids (GOC), and polycarboxylate functionalized graphene nanoplatelets (GN), were compared as biomolecule carrier matrices. Detailed spectroscopic analyses showed that $\mathrm{GO}$ and GOC were similar in composition and functional groups content, and very different to $\mathrm{GN}$, while divergent morphological characteristics were observed for each nanomaterial through microscopy analyses. The commercial alpha-L-rhamnosidase RhaB1 from the probiotic bacterium Lactobacillus plantarum, selected as a model biomolecule for its relevant role in the pharma and food industries, was directly immobilized on the different materials. The binding efficiency and biochemical properties of RhaB1-GO, RhaB1-GOC, and RhaB1-GN composites were analyzed. RhaB1-GO and RhaB1-GOC showed high binding efficiency, while the enzyme loading on $\mathrm{GN}$, not tested in previous enzyme immobilization studies, was low. The enzyme showed contrasting changes when immobilized on the different material supports. The effect of $\mathrm{pH}$ on the activity of the three RhaB1 immobilized versions was similar to that observed for the free enzyme, while the activity-temperature profiles and the response to the presence of inhibitors varied significantly between the RhaB1 versions. In addition, the apparent $\mathrm{Km}$ for the immobilized and soluble enzymes did not change. Finally, the free RhaB1 and the immobilized enzyme in GOC showed the best storage and reutilization stability, keeping most of its initial activity after 8 weeks of storage at $4^{\circ} \mathrm{C}$, and 10 reutilization cycles respectively. This study shows, for the first time, that distinct commercial graphene derivatives can influence differently on the catalytic properties of an enzyme during its immobilization.

\section{Keywords}


Graphene, biocatalysis, immobilization, alpha-L-rhamnosidase, ATR-FTIR

\section{Introduction}

Carbon based nanomaterials form a family of carbon derived particles, including fullerene, graphene, carbon-nanofibers, carbon-nanotubes, carbon-black, carbon-onions, and others ${ }^{12}$. These materials have become the focus of attention of biochemistry and biomedicine researchers due to their unique chemical and physical properties (e.g. surface chemistry, electro-mechanical properties, structural features, etc.), which make them suitable to be used in a number of applications from the technical, medical, environmental and agricultural fields ${ }^{3,4}$. Most of these applications involve the interaction of these nanomaterials with biomolecules (e.g. polypeptides), which due to their structural complexity and composition variability, make prediction of the behavior of the formed carbon-biomolecule composites difficult. Also, despite the relative simplicity of the carbon nanomaterials composition, the variety of protocols developed to produce them might have an impact on the composition of the end products. Thus, the properties of a certain carbon-biomolecule composite might vary depending on the origin of the nanomaterial used, which would make a screening of different options to choose the best performing one for a certain application advisable. Since the first report on mechanical exfoliation of monolayer graphene in $2004^{5}$, interest in this material has increased dramatically, and recent developments have led to the commercial availability of "pristine" graphene and different derivatives, including different types of graphene oxide (GO). Lately, the potential of graphene and its derivatives as biomolecule carriers has also been an important focus of interest for researchers. For instance, it has been shown that both graphene and graphene oxide are capable of binding to different amphiphiles like peptides, polysaccharides and fatty acids, showing differential binding affinities depending on the type of graphene derivative and biomolecule ${ }^{6}$. In this sense, reports comparing the performance of different derivatives from commercial sources when interacting with a selected biomolecule, and their effect on its biochemical properties, are lacking. Also, the fact that the materials used in previous studies are mostly homemade makes it challenging to achieve highly reproducible protocols.

One application that has received the attention of academic researchers and industry is the immobilization of enzymes on solid carriers, since it leads to several benefits for biocatalysis, including an efficient recovery and separation of the reaction product. In addition, the immobilization of enzymes on solid carriers minimizes the contamination of the product, while giving the possibility of reutilization of the biocatalyst, which will increase the cost efficiency of the transformation process and enhance the safety of the material handling (i.e. by preventing the appearance of allergies) ${ }^{7-9}$. Enzymes of microbial origin are nowadays widely applied in a vast number of industrial processes. In fact, their use has been continuously rising during the last decades due to several factors, including the increased availability of biocatalysts tailored to new applications, and the need of a shift towards the use of more sustainable processes in different industrial fields ${ }^{10}$. However, due to the nature of the biocatalysts, the implementation of biocatalytic steps in industrial processes can provoke certain problems as well ${ }^{10,11}$. These 
problems can be partially overcome by using immobilized versions of the enzymes of interest. In addition, the immobilization matrix can influence the biochemical properties of the enzyme, sometimes in a positive manner, for instance increasing its performance in non-aqueous solvents, and/or enhancing its stability (heat organic solvents, autolysis). Therefore, graphene derivatives with distinct properties might also have different influence on the biocatalytic characteristics of an enzyme. However, although the immobilization of a number of enzymes in a variety of functionalized graphene derivatives has been studied during the last years ${ }^{12-18}$, the performance of distinct commercial graphene derivatives and their influence on the catalytic characteristics of a particular enzyme have never been compared.

In this research work, we studied the influence of commercially available carbon-derived nanomaterials on the biochemical properties of an alpha-L-rhamnosidase (GH78), a commercial enzyme of industrial interest produced by the probiotic bacterial strain Lactobacillus plantarum. Alpha-L-rhamnosidases comprise a family of enzymes with many potential applications in the synthesis of pharmaceutical, cosmetic and food products ${ }^{19}$, and those produced by probiotic bacterial strains have received attention in recent studies ${ }^{20-22}$. GH78 enzymes are of particular relevance in the transformation of steroids, antibiotics, and other bioactive molecules with Lrhamnose glycosidic bonds. Also, in combination with beta-D-glucosidase, the enzyme cocktail nariginase is formed, and it can be used as a debittering agent in citrus juices, and to enhance the aroma of wine. Immobilization studies focusing on this enzyme and the nariginase complex have been done, but mainly through encapsulation approaches, with materials different than nanoparticles ${ }^{19,23-26}$. This method allows the generation of an optimal microenvironment for the enzyme through the modification of the encapsulation material, but its practical use is rather limited as, depending on the support material used, mass transfer limitations of the substrate or enzyme leakage can occur ${ }^{8}$. Physical adsorption, which makes use of the physical interactions generated between the carrier and the enzyme (including van der Waals forces, ionic interactions and hydrogen bonds), is the most popular approach for enzyme immobilization ${ }^{8,27}$. This approach typically does not change the native structure of the enzyme, as its active sites are not disturbed, thus allowing to retain its activity ${ }^{28,29}$. In addition, this chemical-free enzyme binding approach allows a better understanding of how the support material can influence the catalytic properties of the selected enzyme. In the present study we thoroughly characterized commercial monolayer graphene oxide, graphene oxide nanocolloids, and polycarboxylate functionalized graphene nanoplatelets, and analyzed, for the first time, the biochemical properties of the Lactobacillus plantarum alpha-L-rhamnosidase enzyme RhaB1 after its direct immobilization on each of these carbon derived nanomaterials.

\section{Materials and Methods}

\section{Materials and reagents}

Most of the chemicals and reagents were purchased to SIGMA and Acros Organics. The graphene derivatives were obtained from different suppliers as well: Graphene oxide 
nanocolloids (ref: 795534; lot: MKBT5205V) and graphene nanoplatelets polycarboxylate functionalized (ref: 806625; lot: MKBW5736V) were purchased to SIGMA, and monolayer graphene oxide (C309/GORB014/D1) was purchased to Graphenea. The alpha-Lrhamnosidase RhaB1 from Lactobacillus plantarum was obtained from Megazyme.

\section{ATR-FTIR analysis}

IR spectra were recorded on dry solid samples in the $4000-400 \mathrm{~cm}^{-1}$ region by a JASCO FT-IR 4200 spectrophotometer equipped with a Single Reflection ATR PRO ONE device. Each of the graphics is the result of overlapping 128 scans with a $4 \mathrm{~cm}^{-1}$ resolution.

\section{Raman, XPS, XRD analysis}

X-ray diffraction analysis (XRD) was done using a Bruker D8 Advance diffractometer equipped with a Sol-X detector and Cu Ka radiation $(\lambda=1.54178 \AA$ ). The powders have been dispersed into an amorphous plastic sample holder and the measures performed in the angular range of 5 - $70^{\circ} 2 \theta$. The X-ray photoelectron spectroscopy (XPS) was done by the SGlker unit at the University of the Basque Country (UPV/EHU), using a SPECS system, equipped with a Phoibos 150, on powders deposited into glass slides. The Raman analysis was done using an Alpha300R-Alpha300A AFM Witec instrument, using samples deposited into glass slides.

\section{AFM and TEM analysis}

AFM images were collected in tapping mode Alpha300R-Alpha300A AFM Witec instrument, using Arrow ${ }^{\mathrm{TM}} \mathrm{NC}$ cantilevers with a tip radius $<10 \mathrm{~nm}$ and a force constant of $42 \mathrm{~N} / \mathrm{m}$. Samples were deposited on a mica surface from aqueous solutions by drop casting. TEM analysis was performed at the Microscopy Unit from the University of Valladolid, using a JEOL JEM-1011 HR TEM coupled with a Gatan Erlangshen ES1000W camera. Samples were deposited on Lacey Carbon Type-A, 300 mesh, copper grids.

\section{Z-potential determination}

The z-potential determination was done at Nanovex Biotechnologies S.L., using a Zetasizer Nano ZS90 (Malvern Instruments) and the M3-PALS method. The graphene derivative suspensions $(650 \mu \mathrm{g} / \mathrm{mL})$ were sonicated for 5 minutes prior to the analysis.

\section{Circular dichroism determination}


1

2

3

4

5

6

7

8

Circular dichroism (CD) spectra were acquired at the Research Technical Services from the University of Alicante, with a JASCO J-810 CD spectrophotometer at $25^{\circ} \mathrm{C}$. Free RhaB1, GOCRhaB1, GO-RhaB1 and GN-RhaB1 were prepared in sodium phosphate buffer $25 \mathrm{mM}(\mathrm{pH} 6.5)$ and the spectra was recorded from 200 to $450 \mathrm{~nm}$ using $1 \mathrm{~mm}$ path length quartz cells, with a scan rate of $50 \mathrm{~nm} \mathrm{~min}^{1}$.

\section{Enzyme immobilization}

Concentrated stocks of the alpha-L-rhamnosidase RhaB1 and the three selected graphene derivatives were prepared in sodium phosphate buffer $25 \mathrm{mM}\left(\mathrm{pH} \mathrm{6.5)}\right.$, and stored at $4^{\circ} \mathrm{C}$. Prior to the immobilization reaction, the nanomaterial suspensions were sonicated. The enzyme binding reactions were prepared in microcentrifuge tubes (final volume $250 \mu \mathrm{L}$ ) by dissolving aliquots of the enzyme solution in the nanomaterials suspensions, to achieve final enzyme concentrations of $600 \mu \mathrm{g} / \mathrm{mL}$ and $100 \mu \mathrm{g} / \mathrm{mL}$, reacting with a fixed graphene nanoparticle concentration $(650 \mu \mathrm{g} / \mathrm{mL})$. The reactions were incubated in an Eppendorf Thermomixer instrument, during 14 hours, under constant gentle shaking (300 rpm), at $4^{\circ} \mathrm{C}$. Afterwards, the bionanocomposites were separated from the reaction supernatants, and subsequently washed three times with sodium phosphate buffer $25 \mathrm{mM}(\mathrm{pH} 6.5)$. All reactions were done by duplicate.

\section{Enzyme activity determination}

The alpha-L-rhamnosidase activity was assayed using 4-nitrophenyl-alpha-L-rhamnopyranoside (pnpR) as substrate. The substrate solution consisted of $65 \mu \mathrm{l}$ of 1,6 mM pnpR dissolved in 25 $\mathrm{mM}$ phosphate buffer ( $\mathrm{pH} \mathrm{6,5).} \mathrm{To} \mathrm{start} \mathrm{the} \mathrm{enzymatic} \mathrm{reaction,} 10 \mu \mathrm{L}$ of an enzyme dilution containing $7,5 \mathrm{mg} / \mathrm{mL}$ of bovine serum albumin (BSA) was added to the substrate solution on 96 $\mathrm{F}$ microwell plates, which were incubated in agitation at $50^{\circ} \mathrm{C}$. After 15 minutes, sodium carbonate $0,25 \mathrm{M}(75 \mu \mathrm{L})$ was added to stop the reaction. Absorbance was measured spectrophotometrically at $405 \mathrm{~nm}$. Enzyme concentration determinations were performed through Bradford analysis, following the supplier indications.

The binding percentage of RhaB1 on different graphene derivatives was determined using the activity values of the free enzyme suspensions prior to the immobilization reactions ("Free enzyme activity"), and the supernatants recovered after the enzyme immobilization reaction, which contain the unbound enzyme ("Supernatant activity"), using the following formula:

$$
\text { Binding percentage }=\frac{\text { Free enzyme activity }- \text { Supernatant activity }}{\text { Free enzyme activity }} \times 100
$$


The Michaelis-Menten behaviour of the free and the immobilized enzymes was determined by measuring the velocity of the enzymatic reaction at different concentrations of pnpR (1-15 mM) using standard conditions.

The enzyme activity profile at different pHs was studied using $100 \mathrm{mM}$ sodium phosphate buffer in a $\mathrm{pH}$ range of $5.5-8$. The enzyme activity profile, at different temperatures $\left(35-60^{\circ} \mathrm{C}\right)$, was determined by performing the reaction at the optimum $\mathrm{pH}$, using the protocol described above. The thermal stability was determined by incubating aliquots of the different RhaB1 versions at two different temperatures $\left(50^{\circ} \mathrm{C}\right.$ and $\left.60^{\circ} \mathrm{C}\right)$, while measuring the enzyme residual activity after $5,10,20,40$ and 60 minutes.

The effects of several inorganic $\left(\mathrm{ZnSO}_{4}, \mathrm{CuSO}_{4}, \mathrm{MnSO}_{4}, \mathrm{CaCl}_{2}, \mathrm{CoCl}_{2}, \mathrm{NaCl}, \mathrm{KCl}\right.$ and sodium metabisulphite) and organic (D-glucose, L-rhamnose, L- tartaric acid, citric acid, acetic acid, ethanol, methanol, propanol and butanol) compounds on the activity of free and immobilized RhaB1 was studied using the enzyme activity determination protocol described above.

\section{Storage stability and reutilization}

To define the stability, aliquots of both free and immobilized RhaB1 were stored in $25 \mathrm{mM}$ sodium phosphate buffer ( $\mathrm{pH} 6.5$ ), at $4^{\circ} \mathrm{C}$. The residual activity was monitored during 8 weeks. The enzyme activity levels recorded at time 0 were used as reference values (100\%). Regarding the reutilization determination, the graphene biocomposites were subjected to several consecutive enzyme reaction cycles. Once a reaction cycle was finished, the biocomposites were recovered by centrifugation and washed two times with sodium phosphate buffer ( $\mathrm{pH} 6.5)$ prior to the next enzyme reaction cycle.

\section{Results and Discussion}

\section{Selection and characterization of different commercial graphene derivatives}

The use of nanomaterials as carriers of enzymes and other biomolecules is the focus of many research studies, due to the exceptional characteristics of these materials, such as high mechanical strength, large surface properties (that allow for more effective interactions with a

variety of biological molecules), low mass transfer resistance, and high loading capacity ${ }^{2,30-33}$. Within the group of carbon derived nanomaterials, graphene oxide has been shown to be very promising in these type of applications ${ }^{34}$. Thus, in the present study we selected two different commercial graphene oxide derivatives, namely monolayer graphene oxide (GO), from the company Graphenea, and graphene oxide nanocolloids (GOC), supplied by Sigma. In addition, we selected polycarboxylate functionalized graphene nanoplatelets (GN), also supplied by Sigma. Prior to their functionalization with the selected biocatalyst, the three materials were thoroughly characterized. To obtain insights into their elemental composition and the presence 
of functional groups their surface chemistry was studied through high resolution X-ray photoelectron spectroscopy (XPS). GO and GOC showed similar $\mathrm{C} / \mathrm{O}$ ratios (1.8 and 2.0 respectively), and different contaminant components were detected in both nanomaterials: $\mathrm{GO}$ had traces of $\mathrm{S}$, whereas $\mathrm{GOC}$ had traces of $\mathrm{Mn}, \mathrm{Ca}, \mathrm{Si}$ and $\mathrm{S}$. Regarding their composition in oxygen functional groups, the obtained spectra suggest the presence of $\mathrm{C}-\mathrm{O}$, and $\mathrm{O}-\mathrm{C}=\mathrm{O}$ (Supplementary table S1). In contrast, GN seemed to have a much higher C/O ratio (27.9), indicating the presence of low oxygen amounts, so the presence of polycarboxylate groups could not be inferred from the spectra analysis. Residual amounts of $\mathrm{Na}$ and/or $\mathrm{P}$ were detected in all three materials, something that could be expected since they were previously equilibrated in sodium phosphate buffer prior to the biofunctionalization step. The three commercial nanomaterials were also characterized through X-ray diffraction analysis (Supplementary figure S1): the pattern corresponding to $G O$ presents the typical broad peak $(001)$ at $2 \theta=10.95^{\circ}$ which indicates a d-spacing of $0.80 \mathrm{~nm}$, in accordance with the data reported in the current literature ${ }^{35}$. The diffractograms recorded for the GOC sample are comparable with the GO pattern, although the 001 peak possesses a broader character. The peak position is centered at $11.05^{\circ}$, which corresponds to an interlayer distance of $0.80 \mathrm{~nm}$. In contrast, the powder X-ray diffraction pattern of the graphene nanoplatelets is characterized by two narrow peaks at $2 \theta$ equal to $26.45^{\circ}$ and $54.55^{\circ}$ of graphite. The 001 Bragg reflection, common for all patterns, is narrower and shifted at lower $2 \theta\left(8.35^{\circ}\right.$, d-spacing $\left.1.06 \mathrm{~nm}\right)$, suggesting that the polycarboxylate groups present in the graphene nanoplatelets significantly increase the average interlayer spacing.

The FTIR spectra of the different graphene derivatives were analysed to obtain additional insights into their functional groups profile (Figure 1a). As a whole, the spectra are weak and unresolved, as observed for these types of compounds ${ }^{36-38}$. Regarding $\mathrm{GO}$ and GOC materials, taking into account the presence of $\mathrm{C}=\mathrm{C}$ ( $\mathrm{sp}^{2}$ bonded carbons), $\mathrm{C}-\mathrm{C}$ ( $\mathrm{sp}^{3}$ bonded carbons), alkoxy $\mathrm{C}-\mathrm{O}-\mathrm{H}$, ether and epoxy $\mathrm{C}-\mathrm{O}-\mathrm{C}$, carbonyl $\mathrm{C}=\mathrm{O}$, and ester and carboxy $\mathrm{C}(=\mathrm{O})-\mathrm{O}$ functional groups, an assignment for the main bands is given, according to those reported in literature ${ }^{38,39}$. A broad band in the $3500-3200 \mathrm{~cm}^{-1}$ region would correspond to the stretching $v(\mathrm{O}-\mathrm{H})$ modes coming from alcohol or hydroxyl acid fragments or, wherever the intensity of the band drastically increases, humidity from water in samples. Weak bands around $1805 \mathrm{~cm}^{-1}$ are characteristic of organic cyclic carbonates (as vinylene or ethylene ones) (SDBSWeb: http://sdbs.db.aist.go.jp (National Institute of Advanced Industrial Science and Technology, $16 / 06 / 2017)$ ). However, in these compounds, these signals have been traditionally assigned to $v(\mathrm{C}=\mathrm{O})$ groups in non-conjugated ketones ${ }^{39}$. The medium-sized band around $1715 \mathrm{~cm}^{-1}$ is attributed to $v(\mathrm{C}=\mathrm{O})$ vibrations in the carboxylic $(\mathrm{COOH})$ moieties. The band often appearing at $1630 \mathrm{~cm}^{-1}$ in wet samples is usually due to the $\delta(\mathrm{H}-\mathrm{O}-\mathrm{H})$ modes of the water molecule. This band uses to resolve as a shoulder in dry samples, as the occluded water in them, but other contributions could be obscured behind it. The minimum around $1585 \mathrm{~cm}^{-1}$ could be attributed to both the contributions of the $v(\mathrm{COO})$ and $v(\mathrm{C}=\mathrm{C})$ modes, for instance in $v\left(\mathrm{C}=\mathrm{C}-\mathrm{COO}^{-}\right)$ moieties ${ }^{40}$. The band around $1365 \mathrm{~cm}^{-1}$ has been ascribed to a combination of $\delta(\mathrm{C}-\mathrm{O}-\mathrm{H})$ 
and $v(C=C)$, characteristic of regions with several phenyl groups located nearby ${ }^{39}$. Some authors assign the medium band in the $1225-1210 \mathrm{~cm}^{-1}$ to $\mathrm{v}(\mathrm{C}-\mathrm{O})$ from $(\mathrm{C}-\mathrm{OH})$ modes and epoxy $v(\mathrm{C}-\mathrm{O}-\mathrm{C})$ groups $^{29}$. Bands at $1070-1020 \mathrm{~cm}^{-1}$ could arise from phenol and hydroxyl $v(\mathrm{C}-\mathrm{O})$ vibrations, while those around $980-930 \mathrm{~cm}^{-1}$ have been attributed to $v(\mathrm{C}-\mathrm{O})$ etheric rings. The observed differences between $\mathrm{GO}$ and GOC are not significant. To ratify the nature of some of the bands observed in GO and GOC, we checked the influence of the acidity of the medium on the intensity and positions of the bands of the colloidal derivative (GOC), represented in Figure 1b. Despite the low resolution of the sample acidified with diluted aqueous $\mathrm{HCl}$ solution, there is a clear increase in the intensity of the bands at $1715,1350-1370$ and $1020-1025 \mathrm{~cm}^{-1}$ and a decrease in that around $1570 \mathrm{~cm}^{-1}$, which is in good agreement with a greater amount of $\mathrm{COOH}$ carboxylic acid and hydroxyl groups.

Regarding the GN material, the lack of noticeable spectroscopic features in the FTIR spectra of this material is evidence for a relatively low amount of oxygen-containing functional groups, as observed before in the XPS analysis.

To further define the composition of GO and GOC, and to get insights into their structural features, both nanomaterials were analysed by Raman spectroscopy as well (Supplementary figure S2a). As expected, GO and GOC showed the characteristic graphene oxide bands D and $\mathrm{G}^{41,42}$, which were fitted with a Lorentzian function prior to their analysis. All prominent bands appeared at upper frequencies in GOC, and their relative intensity was also higher in the colloidal nanomaterial. This suggests that GOC accumulates a higher number of defects. Also, the observed shift in the $D$ band suggests a different reorganization of the hexagonal lattice of both materials, as well as a greater concentration of structural defects and higher disorder of the atomic bonds in GOC ${ }^{42,43}$.

Finally, since the charge of the nanomaterials could influence the adsorption of the enzyme, their zeta-potential was measured. When suspended in the enzyme immobilization buffer (sodium phosphate $25 \mathrm{mM}, \mathrm{pH}$ 6.5), selected according to the enzyme supplier instructions to obtain the optimal enzyme activity, the three materials showed to have a very similar charge, between -44 and $-46 \mathrm{mV}$, which is in the range of values previously reported ${ }^{44}$.

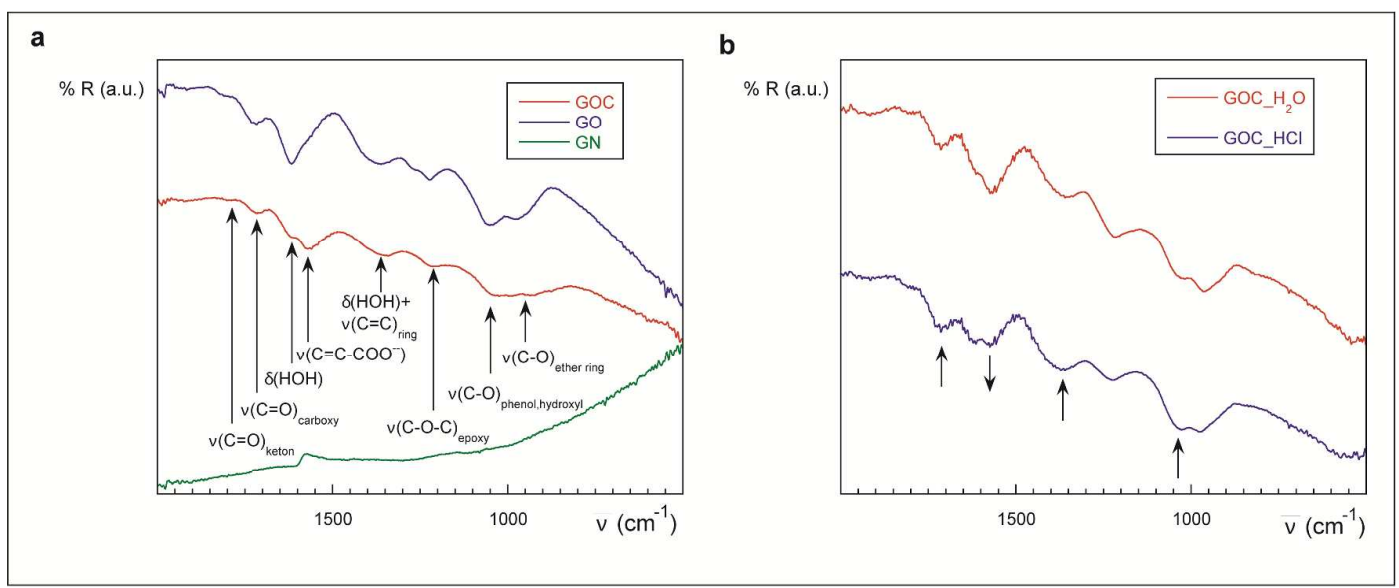



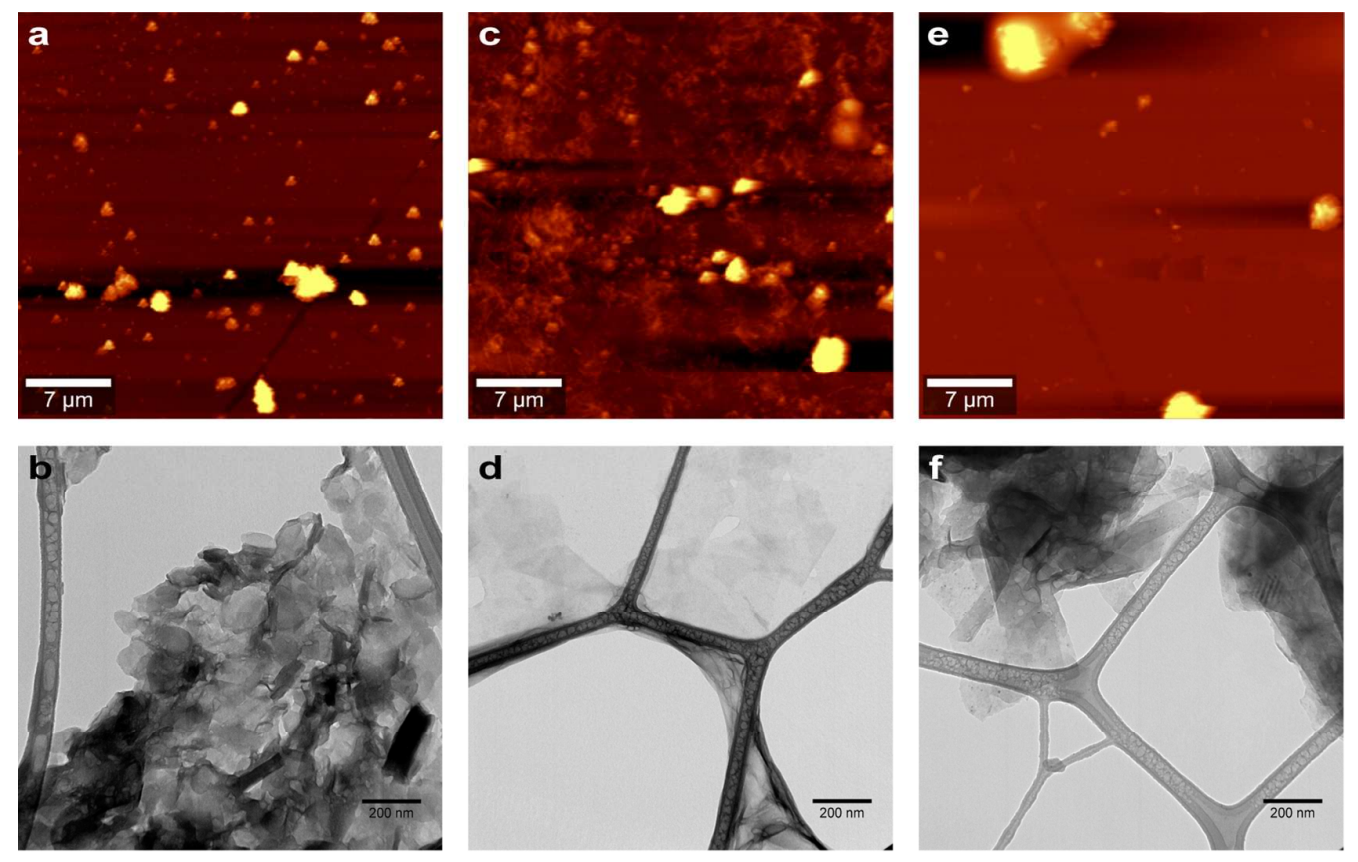

Figure 2. AFM and TEM analysis of $\operatorname{GOC}(a, b), G O(c, d)$ and $G N(e, f)$. Graphene solutions with a final concentration of $20 \mu \mathrm{g} / \mathrm{mL}$ were deposited by drop casting on a mica surface and carbon coated copper grids respectively. 


\section{Inmobilization of the alpha-L-rhamnosidase RhaB1 in different graphene derivatives}

The commercial alpha-L-rhamnosidase RhaB1 from Lactobacillus plantarum (specific activity: 190 units/mg protein) was selected for immobilization on the different graphene derivatives. Alpha-L-rhamnosidases have shown to be potentially useful in pharmaceutical and food industries, in processes related to the enhancement of the health benefits of naturally occurring plant flavonoids or by improving the taste and flavour of different food products ${ }^{47-49}$. As described above, several studies have focused on the immobilization of alpha-Lrhamnosidases, but mostly through encapsulation approaches, and never using carbon derived nanoparticles. The first step towards the analysis of the catalytic properties of RhaB1 when directly immobilized on graphene derivatives was to evaluate its binding capacity to the different test materials. Two different enzyme concentrations, high $(600 \mu \mathrm{g} / \mathrm{mL})$ and low $(100 \mu \mathrm{g} / \mathrm{mL})$, were incubated with a fixed graphene nanoparticle concentration $(650 \mu \mathrm{g} / \mathrm{mL})$ and different graphene biocomposites were obtained (for more details see Materials and Methods). To calculate the percentage of enzyme bound to the different materials, the rhamnosidase activity of the supernatants recovered after the immobilization reaction was determined (unbound protein), and compared to that of RhaB1 solutions at $600 \mu \mathrm{g} / \mathrm{mL}$ and $100 \mu \mathrm{g} / \mathrm{mL}$ (Table 1). Table 1 displays the percentage of RhaB1 bound in the different biocomposites, the amount of enzyme immobilized per $\mathrm{mg}$ of nanomaterial, and the relative activity retained after the immobilization. RhaB1 was bound with high efficiency to GO and GOC at both high and low concentrations. In the case of GN, only a low proportion of the enzyme was bound to the substrate, particularly when the enzyme was present at high concentration. This result indicates that GOC and GO have a high loading capacity for RhaB1, while GN has a poorer performance when used as a carrier for this enzyme. GO and GOC showed a higher loading capacity than that reported for different graphene derivatives in similar applications ${ }^{18,50-52}$. The relative RhaB1 activity retained in the biocomposites after the immobilization reaction was also determined by using the enzyme activity of the free RhaB1 high and low enzyme suspensions as reference (Table 1). Interestingly, in case of GOC and GO, when lower enzyme concentrations were used, the retained relative RhaB1 activity was lower, too. Different enzyme-nanoparticle ratios, equivalent to a different solution chemistry, could result in different biocomposite aggregation states ${ }^{53}$, which could have an influence on the relative activity retained by the enzyme after its immobilization.

\begin{tabular}{|c|c|c|c|c|}
\hline Sample & $\begin{array}{c}\text { RhaB1 binding } \\
\text { percentage (\%) }\end{array}$ & $\begin{array}{c}\text { RhaB1 load } \\
(\mu \mathbf{g} / \mathbf{m g})\end{array}$ & $\begin{array}{c}\text { Relative activity } \\
\text { retained by loaded } \\
\text { RhaB1 (\%) }\end{array}$ & $\begin{array}{c}\text { Specific activity } \\
\text { (U/mg protein) }\end{array}$ \\
\hline $\begin{array}{c}\text { GOC-RhaB1 } \\
(600 \mu \mathrm{g} / \mathrm{mL})\end{array}$ & $98,9 \pm 3,2$ & $912,9 \pm 29,5$ & $91,7 \pm 4,3$ & $174,2 \pm 8,7$ \\
\hline GOC-RhaB1 & $98,1 \pm 3,6$ & $150,9 \pm 5,6$ & $58,7 \pm 5,5$ & $111,5 \pm 10,5$ \\
\hline
\end{tabular}


To confirm the enzyme binding, and to analyze the morphological characteristics of the biocomposites, additional spectroscopy and microscopy analyses were performed on GOCRhaB1, GO-RhaB1 and GN-RhaB1. The infra-red spectra of the enzyme supported on GO and GOC were very different to the bare nanomaterials, containing several high intensity bands which were absent in the graphene matrices, as can be seen in Figure 3. The intense and medium bands around 3275, 1634, 1530-1515, 1455-1445, 1390, 1235, 1150-1055 and 930 $\mathrm{cm}^{-1}$ have been attributed to $v(\mathrm{O}-\mathrm{H}) / v(\mathrm{~N}-\mathrm{H})$, amide I, amide II, $v(\mathrm{COO}-) / v(\mathrm{C}=\mathrm{C})$, amide III, amide III, $\delta(\mathrm{N}-\mathrm{H})$ and $\gamma(\mathrm{N}-\mathrm{H})$ vibration modes, respectively, which is in good agreement with previously reported studies ${ }^{54-58}$. Also, some researchers have assigned bands around 1050 $\mathrm{cm}^{-1}$ to the formation of hydrogen bonds between protein and graphene ${ }^{59}$. In contrast, no evidence of enzyme adsorption to graphene nanoplatelets could be obtained from infra-red measurements in the same experimental conditions, probably due to the low levels of enzyme bound to the nanomaterial, as shown in the binding percentage determination assay. 
Figure 3. IR spectra of GOC-RhaB1 (red) and GO-RhaB1 (blue), in logarithmic scale for the $4000-400 \mathrm{~cm}^{-1}$ region.

To get additional insights into the enzyme adsorption phenomenon of each of the selected graphene derivatives we also made Raman measurements in the samples with and without bound enzyme. The spectra of $G O$ and $G O C$ bound to RhaB1 show the characteristic $D$ and $G$ bands, which are present in the bare materials too. However, a similar shift towards lower wavenumbers could be observed for GO-RhaB1 and GOC-RhaB1 (Supplementary figure S2b). As previously described ${ }^{41-43}$, this could be due to reorganization of the hexagonal lattice of the carbon atoms with defects when the enzyme is bound to the graphene derivatives. Additional differences observed between the enzyme bound and the bare materials were the ratio increase between $\mathrm{D}$ and $\mathrm{G}$ bands on the first group, possibly due to the presence of a greater number of defects, and the clear increase in intensity of the $2 \mathrm{D}$ region, which is an indication of partial stacking of the graphene sheets, possibly caused by the presence of the enzyme ${ }^{42,43}$. Regarding the Raman spectra of $\mathrm{GN}$ and GN-RhaB1, both samples showed the typical graphene characteristics ${ }^{42}$. However, GN-RhaB1 showed a displacement of the $2 \mathrm{D}$ band to a lower wavelength, and both the $2 \mathrm{D}$ band intensity and the ID/IG ratio were higher. These changes could be related to the small amounts of RhaB1 that were immobilized on GN.

To observe possible morphological changes caused by RhaB1 immobilization on GO, GOC and GN, microscopy analyses using AFM and TEM were done. The AFM scans of GO-RhaB1 and GOC-RhaB1 showed clear differences when compared to those obtained from the bare materials. In case of GN-RhaB1, differences were not as evident, probably due to the low enzyme binding efficiency observed. However, the low resolution of the scans made it impossible to do a thorough analysis of the nanomaterial-enzyme composites structure (Supplementary figure S3). TEM imaging allowed to see evident differences in the surface topography of the nanomaterials before and after RhaB1 immobilization, and gave more information on how the bound enzyme interacted with the different nanomaterials. In the case of 

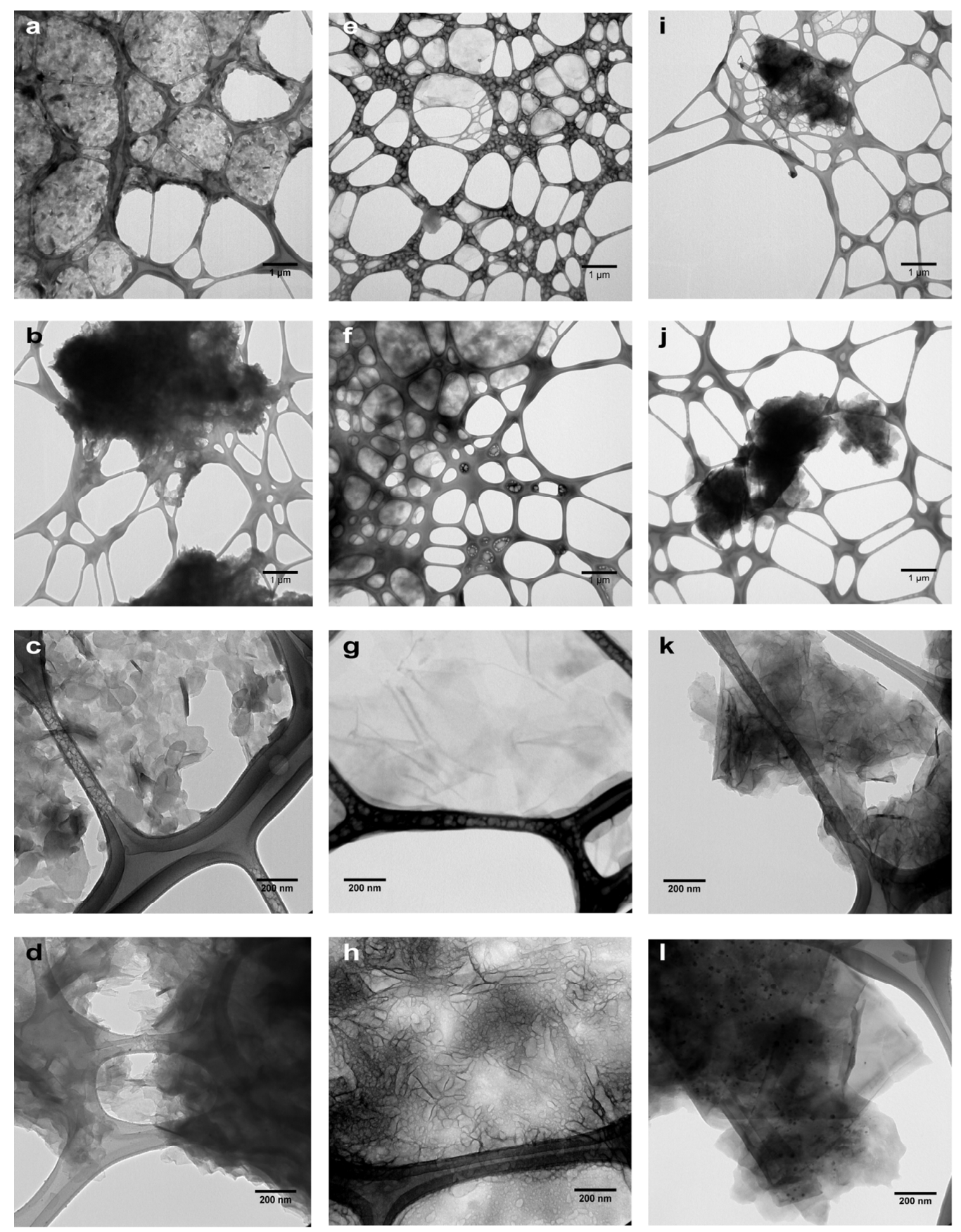
Figure 4. TEM analysis of GOC (a, c), GOC-RhaB1 (b, d), GO (e, g), GO-RhaB1 (f, h), GN (i, k) and GN-RhaB1 (j, I). Graphene solutions with a final concentration of $20 \mu \mathrm{g} / \mathrm{mL}$ were deposited by drop casting on carbon coated copper grids.

To determine possible RhaB1 structural changes due to the enzyme adsorption on the different materials, a circular dichroism (CD) spectroscopy analysis was done. The CD spectra of free RhaB1, GOC-RhaB1, GO-RhaB1 and GN-RhaB1 were similar (Supplementary Figure S4). An analysis of the far UV-region allowed the identification, in all samples, of a positive band at 205 $\mathrm{nm}$, and a negative band around $220 \mathrm{~nm}$, suggesting that minimum changes in the secondary structure of RhaB1 occurred as a consequence of its interaction with the different graphene derivatives, as previously reported ${ }^{60}$. To have further insights into possible conformational changes occurring in the immobilized RhaB1, the affinity of the different graphenerhamnosidase composites towards the synthetic 4-nitrophenyl alpha-L-rhamnopyranoside was determined by studying their activity in the presence of different concentrations of the substrate. The obtained results showed that free RhaB1 has a $\mathrm{Km}$ of around $6 \mathrm{mM}$, as reported previously by Beekwilder et al. (2009), while the same values were obtained for the different RhaB1 immobilized versions. The influence of the immobilization process on the substrate affinity of different enzymes has been reported previously with a variable outcome, ranging from no changes to increased values of almost two orders of magnitude ${ }^{18}$.

\section{Effect of temperature on RhaB1 activity and its different graphene composites}

The enzymatic activity of free and immobilized enzymes as a function of temperature was studied (Figure 5a). Maximal activity for free RhaB1 was detected at $48^{\circ} \mathrm{C}$, which is very similar to the one reported in a previous study ${ }^{48}$. The remaining activity of the free enzyme at $60^{\circ} \mathrm{C}$ was close to $70 \%$. This result also fits with previous reports, indicating a relatively high activity of the enzyme at temperatures over $50^{\circ} \mathrm{C}{ }^{48}$. When immobilized on GOC, the enzyme activity profile did not show any significant changes. However, when immobilized on GO and GN, a change in the optimal temperature and in the activity profile of the enzyme could be observed. The optimal temperature of RhaB1 immobilized on $\mathrm{GO}$ and $\mathrm{GN}$ was $40^{\circ} \mathrm{C}$ and $50^{\circ} \mathrm{C}$ respectively. In the case of RhaB1-GO, the enzyme showed a lower activity at temperatures above $40^{\circ} \mathrm{C}$, when compared to the rest of the RhaB1 versions studied. In contrast, RhaB1-GN displayed a significantly lower activity at temperatures below $45^{\circ} \mathrm{C}$ when compared to the other conditions tested. Previous studies, in which different alpha-L-rhamnosidases were immobilized on substrates different to graphene, also showed variable effects in the temperature activity profile of the enzymes ${ }^{24,61}$. In addition, other studies, in which different enzymes were immobilized on functionalized graphene derivatives, also showed a change in their activity profile at different temperatures ${ }^{30,50,62}$. Amongst other possibilities, this phenomenon could be due to distinct aggregation kinetics of the enzyme-graphene composites, which would affect the 
measurable RhaB1 activity. Recent findings show that both temperature and the solution chemistry have an impact on the aggregation kinetics of graphene in aquatic environments ${ }^{53}$. GO, GOC and GN have shown differences in morphology and composition, and TEM analysis showed distinct nanomaterial-enzyme interactions as well. Therefore, it is possible that their aggregation state is differently affected under temperature changes, causing differences in the enzyme availability for the substrate.

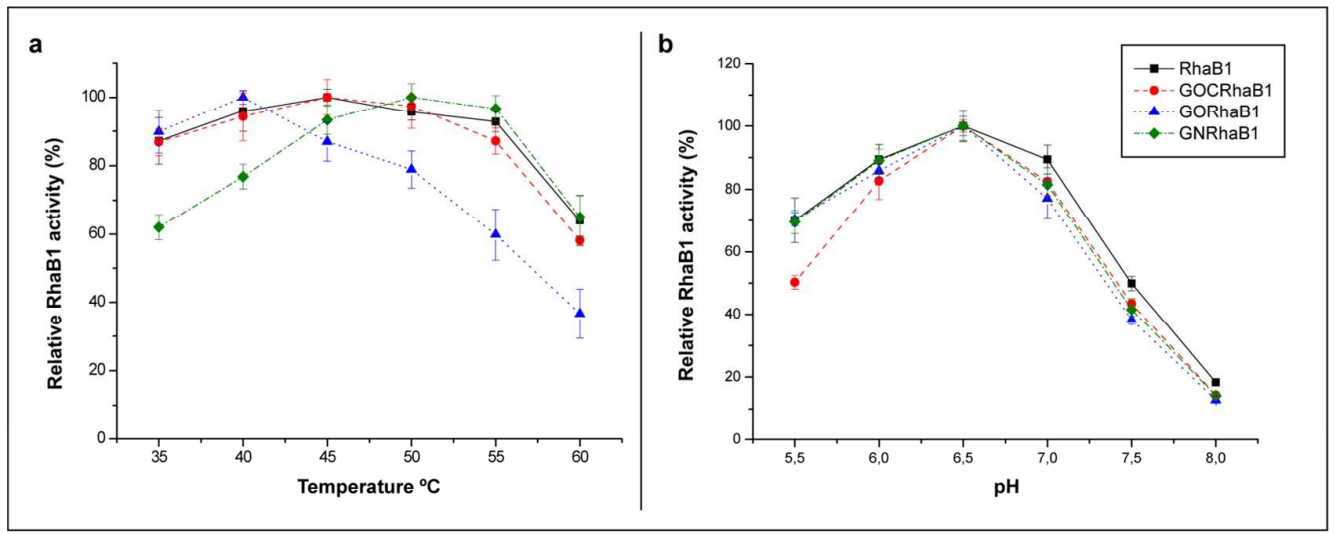

Figure 5. Alpha-L-rhamnosidase activity of free and immobilized RhaB1 on different graphene derivatives as a function of temperature (a) and $\mathrm{pH}(\mathrm{b})$. The error bars are means of four technical replicates, measured in two different samples.

\section{Effect of pH on RhaB1 and its different graphene composite versions}

The $\mathrm{pH}$ optima of free RhaB1 and its different immobilized versions was studied by determining the enzyme activity along a range of different $\mathrm{pHs}$ (for more details see Materials and methods). In all cases the activity of the enzyme was highest at pH 6.5 (Figure $5 \mathrm{~b}$ ). A similar result was previously reported for the free enzyme, when rutin was used as substrate ${ }^{47}$. All RhaB1 versions analysed (free and immobilized) showed a similar activity profile along the different pHs. However, while free RhaB1, and the enzyme immobilized on GN and GO, kept over $60 \%$ of its activity in the $\mathrm{pH}$ range from 5.5 to 7 , the enzyme immobilized on GOC showed a lower residual activity at $\mathrm{pH} 5.5(50 \%)$. In addition, the residual activity that was determined at $\mathrm{pH}$ values higher than 7 was lower than $50 \%$, in all cases. As displayed in Figure 5b, both free RhaB1 and the graphene-enzyme nanocomposites showed comparable activity profiles, with the exception of RhaB1-GOC at pH 5.5. Similar results were reported previously, where rhamnosidases from Clostridium stercorarium and Aspergillus terreus where immobilized on different non-graphene materials ${ }^{24,26,61}$. Nevertheless, immobilization of glycoside hydrolases different from alpha-L-rhamnosidases on graphene derivatives have shown variable results regarding their $\mathrm{pH}$ activity profile when compared to the free enzyme, being clearly altered most of the times ${ }^{30,51,62,63}$. In any case, the graphene nanomaterials selected in these studies are 
quite heterogeneous in terms of composition, which makes it difficult to understand their role on the modification of the enzymes catalytic properties.

\section{Time-dependent stability of RhaB1 graphene composites at different temperatures}

Once the optimal temperature was determined for all RhaB1 versions, their time-dependent stability at different temperatures was also examined. The enzymes were incubated at $50^{\circ} \mathrm{C}$ and $60^{\circ} \mathrm{C}$ for one hour. In the case of the free enzyme, RhaB1 kept over $80 \%$ of its residual activity after an hour of exposure to $50^{\circ} \mathrm{C}$ (Figure 6). In a previous study, RhaB1 showed a lower degree of stability at $45^{\circ} \mathrm{C}$ and $55^{\circ} \mathrm{C}{ }^{48}$. In the present study, the protocol used for quantification of alpha-L-rhamnosidase activity included bovine serum albumin (BSA), while this was not the case in the study performed by Avila and collaborators. BSA can act as an enzyme stabilizer ${ }^{64}$, which could explain the differences in thermal stability observed between the two studies. The enzyme immobilized on GOC showed a comparable behaviour to that of the free enzyme when incubated at $50^{\circ} \mathrm{C}$. However, contrasting changes in thermal stability were observed when the enzyme was immobilized on GO and GN. When immobilized on GO, RhaB1 lost, on average, around $30 \%$ of its activity after an hour of thermal incubation, while the residual activity of the enzyme remained over $90 \%$ when immobilized on GN, showing the highest stability levels among all RhaB1 versions studied (Figure 6a). At $60^{\circ} \mathrm{C}$, the free enzyme became inactive after ten minutes of incubation, while all RhaB1 immobilized versions kept around $15 \%$ residual activity (Figure 6b). Remarkably, the improvement of the thermal stability of other glycoside hydrolases after their immobilization on graphene derivatives has been previously observed in various studies ${ }^{14,30,50,63}$.

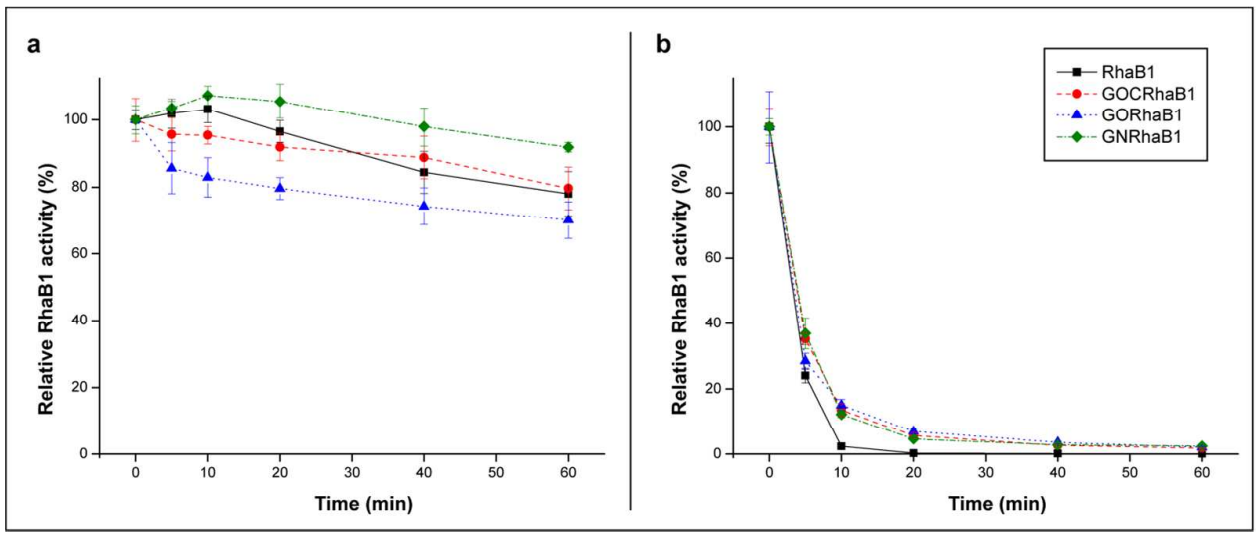

Figure 6. Stability of free and immobilized RhaB 1 at $50^{\circ} \mathrm{C}(\mathrm{a})$ and $60^{\circ} \mathrm{C}(\mathrm{b})$ during a time course incubation of 60 minutes. The error bars are means of four technical replicates, measured in two different samples. 


\section{Effect of potential inhibitors and activators}

The presence of different components in reaction matrices where alpha-L-rhamnosidases can be applied might inhibit their activity ${ }^{65,66}$. The availability of data regarding the influence of potential inhibitors and activators of RhaB1 activity is limited, and their effect could vary due to the enzyme immobilization. Therefore, we studied the effect of a range of components (metal ions, sugars, alcohols, etc.) on the activity of free and immobilized RhaB1. As displayed in Table 2, the divalent cations $\mathrm{Mn}^{2+}, \mathrm{Cu}^{2+}, \mathrm{Zn}^{2+}$ and $\mathrm{Co}^{2+}$ showed an inhibitory effect on the free RhaB1. An inhibitory effect on RhaB1 activity was previously observed for $\mathrm{Mn}^{2+}$ and $\mathrm{Cu}^{2}$ ions ${ }^{48}$. In contrast, the monovalent cations $\mathrm{Na}^{+}$and $\mathrm{K}^{+}$showed an improvement $(27 \%$ and $10 \%$ respectively) of the enzymatic activity of free $\mathrm{RhaB} 1$, while $\mathrm{Mg}^{2+}$ and $\mathrm{Ca}^{2+}$ did not affect the enzyme activity. After its immobilization on the different graphene composites, the stimulatory effect of $\mathrm{Na}^{+}$and $\mathrm{K}^{+}$on RhaB1 activity disappeared. The divalent cations $\mathrm{Mg}^{2+}$ and $\mathrm{Ca}^{2+}$ reduced the activity of all RhaB1-graphene composites, and $\mathrm{Co}^{2+}$ and $\mathrm{Cu}^{2+}$ had an even bigger inhibitory effect. In contrast, the inhibitory effect of the divalent cations $\mathrm{Mn}^{2+}$ and $\mathrm{Zn}^{2+}$ on RhaB1 activity was stronger on the free enzyme. Regarding sodium metabisulfite (200 $\mathrm{mg} / \mathrm{L})$, the presence of this salt barely affected the performance of the free enzyme and the three different composites.

\begin{tabular}{|l|c|c|c|c|}
\hline \multirow{2}{*}{ Component } & \multicolumn{4}{|c|}{ alpha-L-rhamnosidase activity (\%) } \\
\cline { 2 - 5 } & RhaB1 & GOCNF-RhaB1 & GONF-RhaB1 & GNNF-RhaB1 \\
\hline $\mathrm{MnSO}_{4}-\mathrm{H}_{2} \mathrm{O}(1 \mathrm{mM})$ & $5,4 \pm 1,1$ & $57,2 \pm 1,5$ & $59,3 \pm 3,3$ & $18,5 \pm 0,6$ \\
\hline $\mathrm{CuSO}_{4}-5 \mathrm{H}_{2} \mathrm{O}(1 \mathrm{mM})$ & $6,9 \pm 0,7$ & $5,2 \pm 1,5$ & $0,0 \pm 0,5$ & $1,1 \pm 0,4$ \\
\hline $\mathrm{ZnSO}_{4}(1 \mathrm{mM})$ & $37,0 \pm 2,2$ & $53,3 \pm 1,8$ & $53,9 \pm 3,4$ & $38,3 \pm 1,3$ \\
\hline $\mathrm{CoCl}_{2}(1 \mathrm{mM})$ & $74,0 \pm 5,5$ & $63,5 \pm 2,4$ & $63,0 \pm 1,9$ & $50,2 \pm 4,3$ \\
\hline $\mathrm{CaCl}_{2}(1 \mathrm{mM})$ & $91,1 \pm 3,1$ & $84,8 \pm 3,6$ & $87,4 \pm 1,8$ & $78,7 \pm 5,7$ \\
\hline $\mathrm{MgCl}_{2}(1 \mathrm{mM})$ & $101,6 \pm 5,8$ & $83,8 \pm 3,1$ & $91,6 \pm 5,4$ & $71,7 \pm 5,3$ \\
\hline $\mathrm{KCl}(1 \mathrm{mM})$ & $110,1 \pm 6,7$ & $95,3 \pm 3,9$ & $97,7 \pm 6,1$ & $93,3 \pm 2,3$ \\
\hline $\mathrm{NaCl}(1 \mathrm{mM})$ & $127,4 \pm 3,2$ & $95,5 \pm 3,6$ & $98,0 \pm 0,8$ & $97,3 \pm 3,5$ \\
\hline $\begin{array}{l}\text { Sodium metabisulfite } \\
(200 \mathrm{mg} / \mathrm{L})\end{array}$ & $98,6 \pm 1,2$ & $90,0 \pm 4,4$ & $96,1 \pm 4,1$ & $98,6 \pm 8,4$ \\
\hline
\end{tabular}

Table 2. Effect of different inorganic compounds on the activity of free and immobilized RhaB1. The reported values are the averages of four technical replicates, measured in two different samples.

The effect of different organic compounds on the catalytic behaviour of different RhaB1 versions was also tested (Table 3). Two different sugars (glucose and rhamnose), three organic acids (tartaric acid, citric acid and acetic acid), and four alcohols (ethanol, methanol, propanol and 
butanol) were tested at concentrations that resemble those found in a variety of food matrices. In contrast to previous studies reporting the effect of high glucose concentrations on the performance of rhamnosidases ${ }^{66,67}$, RhaB1 kept a relatively high level of activity in the presence of glucose $500 \mathrm{mM}$, while the enzyme-graphene composites showed a higher reduction of their activity. The inhibitory effect produced by rhamnose (100 mM) was stronger, and similar in all cases. In general, methanol, butanol and propanol showed a relatively low influence on the performance of all four RhaB1 versions, while ethanol provoked a more pronounced inhibitory effect on the enzymes, which was higher in case of the RhaB1-graphene composites. Meanwhile, the presence of organic acids substantially reduced the enzyme activity, which could be due to a $\mathrm{pH}$ decrease. The inhibitory effect observed for rhamnose, alcohols and organic acids seem to be usual for most rhamnosidases ${ }^{68,69}$, although some have shown to be more tolerant to ethanol than RhaB1 ${ }^{65,67}$. Regarding the effect of organic solvents on the activity of immobilized enzymes, few studies were found, investigating their effect on the activity of lipases and laccases. In some cases, the immobilized enzymes showed higher activity levels than the free ones, but the results were variable, as observed as well in the present study ${ }^{15,70,71}$. The obtained results show that potential inhibitors and activators may have a different influence on the activity of immobilized enzymes and their free forms. As mentioned before, a recent report shows that changes in the ionic strength and the solution chemistry (including changes of cation types) can have an influence on the stability and aggregation state of graphene derivatives ${ }^{53}$, which could also influence the activity of the biocomposites.

\begin{tabular}{|l|l|l|l|l|}
\hline \multirow{2}{*}{ Component } & \multicolumn{3}{|c|}{ alpha-L-rhamnosidase activity (\%) } \\
\cline { 2 - 5 } & RhaB1 & GOCNF-RhaB1 & GONF-RhaB1 & GNNF-RhaB1 \\
\hline Glucose $500 \mathrm{mM}$ & $84,7 \pm 3,7$ & $66,3 \pm 2,6$ & $60,8 \pm 3,9$ & $66,7 \pm 2,3$ \\
\hline Rhamnose $100 \mathrm{mM}$ & $19,6 \pm 0,8$ & $19,0 \pm 1,7$ & $18,3 \pm 1,7$ & $16,8 \pm 1,3$ \\
\hline L(+)Tartaric acid 0,8 g/L & $15,0 \pm 4,1$ & $5,2 \pm 1,8$ & $7,8 \pm 1,7$ & $9,3 \pm 2,1$ \\
\hline Citric acid 0,8 g/L & $24,5 \pm 5,5$ & $5,4 \pm 1,7$ & $3,8 \pm 0,5$ & $3,0 \pm 0,7$ \\
\hline Acetic acid 0,8 g/L & $74,4 \pm 1,4$ & $28,5 \pm 2,1$ & $30,2 \pm 1,9$ & $31,7 \pm 2,2$ \\
\hline Ethanol 12 \% & $53,8 \pm 1,4$ & $43,7 \pm 3,2$ & $38,7 \pm 1,9$ & $38,2 \pm 2,3$ \\
\hline Methanol 0,6 \% & $88,6 \pm 1,5$ & $100,3 \pm 2,6$ & $99,3 \pm 4,8$ & $91,6 \pm 4,9$ \\
\hline Propanol 0,6 \% & $90,5 \pm 3,3$ & $92,2 \pm 2,7$ & $85,9 \pm 7,7$ & $81,0 \pm 7,5$ \\
\hline Butanol 0,6 \% & $84,8 \pm 5,6$ & $95,2 \pm 4,0$ & $88,5 \pm 7,1$ & $76,0 \pm 2,5$ \\
\hline
\end{tabular}

Table 3. Influence of different organic compounds on the activity of free and immobilized RhaB1. The error bars are means of four technical replicates, measured in two different samples.

\section{Time-dependent stability, leaching and reusability}


1 2 3

The time-dependent stability of the different RhaB1-graphene composites was analyzed by measuring the activity of the different stocks when stored during two months at $4^{\circ} \mathrm{C}$. In addition, the influence of enzyme load on the enzyme stability was evaluated. All RhaB1 versions were stored at $4^{\circ} \mathrm{C}$ for 60 days, and their activity was tested several times during this period. As can be observed in Figure 7, free and immobilized RhaB1 stability showed a clear dependence on protein concentration, as previously reported for other enzymes ${ }^{72,73}$. The free enzyme and RhaB1-GOC suspensions containing a higher enzyme concentration $(600 \mu \mathrm{g} / \mathrm{mL})$ were the only samples that kept $100 \%$ of their activity during the test period. In contrast, the RhaB1-GOC composites obtained with a lower enzyme concentration $(100 \mu \mathrm{g} / \mathrm{mL})$ lost around $30 \%$ activity, while the free enzyme at the same concentration lost $50 \%$. Therefore, GOC showed to have a protective role on RhaB1 stability when the enzyme was loaded at $100 \mu \mathrm{g} / \mathrm{mL}$. The RhaB1-GO sample sets, obtained from both $600 \mu \mathrm{g} / \mathrm{mL}$ and $100 \mu \mathrm{g} / \mathrm{mL}$ immobilization reactions, gradually reduced their rhamnosidase activity along the storage period. Initially, the samples with a lower RhaB1 load $(100 \mu \mathrm{g} / \mathrm{mL})$ showed a faster activity decrease. However, after 60 days of storage, the remaining activity levels in both sample sets were very similar, maintaining around $30 \%$ of the initial activity in all cases. Similarly, when immobilized on GN, RhaB1 also suffered a decrease of its activity along the whole storage period, finally keeping around $50 \%$ of the initial activity in both $600 \mu \mathrm{g} / \mathrm{mL}$ and $100 \mu \mathrm{g} / \mathrm{mL}$ sample sets. In this case, there were no clear differences between $\mathrm{GN}$ and GN-RhaB1 in terms of activity reduction rhythm. As described before, the RhaB1 binding on polycarboxylate functionalized GN was low, regardless of the amount of enzyme used in the immobilization process. This could explain the fact that no clear differences are observed in stability changes between the different GN samples. RhaB1 loaded on $\mathrm{GOC}$ and $\mathrm{GO}$ at a lower concentration lost its activity faster than when loaded in higher amounts, which indicates the relevance of this parameter to keep RhaB1 stability along time. The GOC nanomaterial showed the best performance to keep the stability of RhaB1, at both enzyme concentrations tested, when stored at $4^{\circ} \mathrm{C}$. 


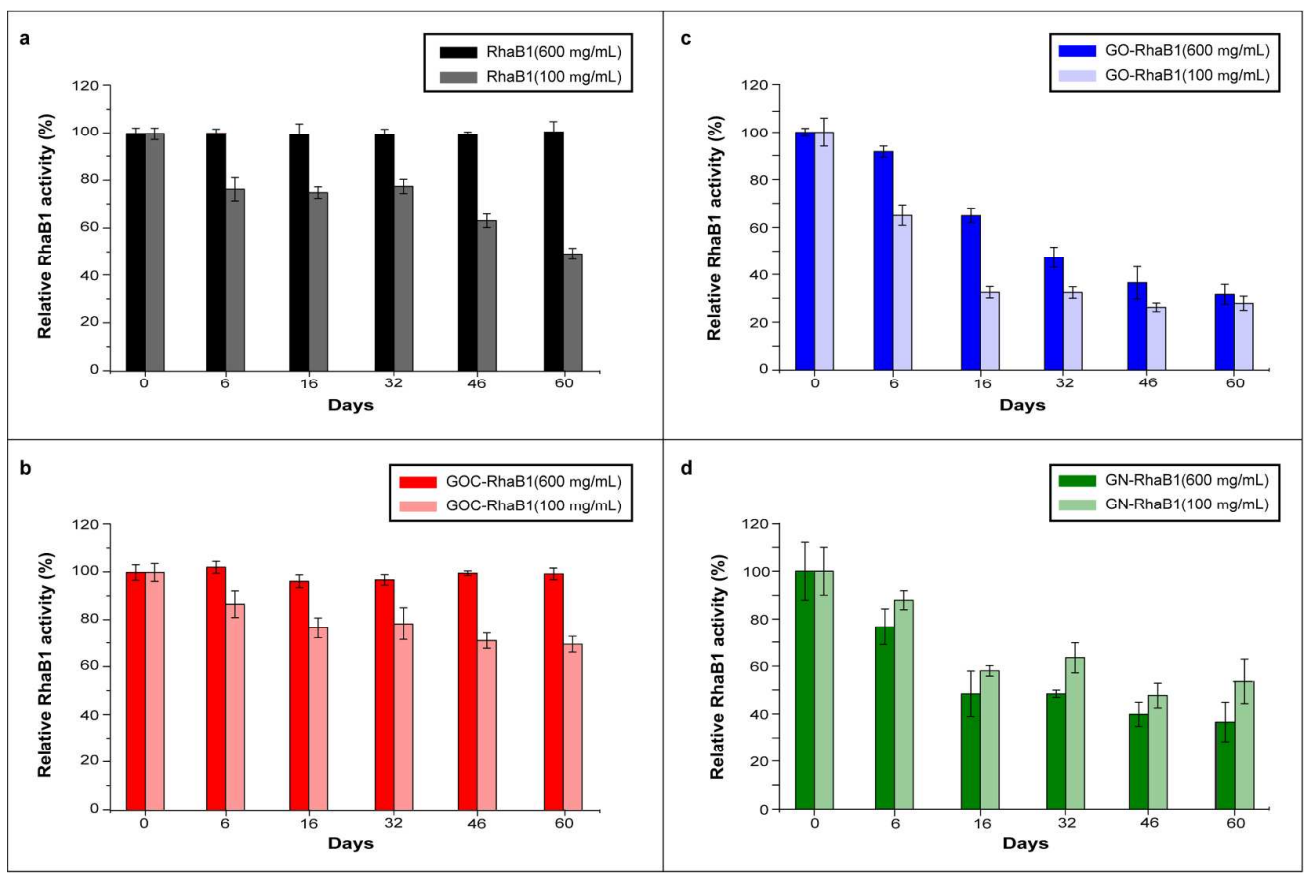

Figure 7. Time dependent alpha-L-rhamnosidase activity of free RhaB1 (a), and immobilized, with different initial concentrations, on GOC (b), GO (c), and GN (d). The error bars are means of four technical replicates, measured in two different samples.

The reusability of GO-RhaB1, GOC-RhaB1 and GN-RhaB1 was also compared in this study, as it is an important feature of the immobilized enzymes cost efficiency. The three biocomposites were subjected to 10 reutilization cycles and, as described below, they showed similar differences to those observed in the storage stability assay. GOC-RhaB1 had the highest reutilization stability, keeping more than $90 \%$ of the initial RhaB1 activity after 10 cycles of repeated use. Initially, GO-RhaB1 also showed to be highly stable, being fully active during the first 5 utilization cycles. Afterwards, the enzyme activity started to decline steadily until the $10^{\text {th }}$ cycle, when only the $60 \%$ of its initial activity remained. GN-RhaB1 was the less efficient biocomposite in terms of reusability: RhaB1 lost one third of its activity after the fourth cycle, although it still kept the $50 \%$ of its activity at the end of the assay (Figure 8 ). The reusability of similar biocomposites from previous reports has shown to be a variable parameter. Still, in many cases the studied enzymes lose a significant proportion of their initial activity after 10 reaction cycles $^{50,51,63,74}$. 


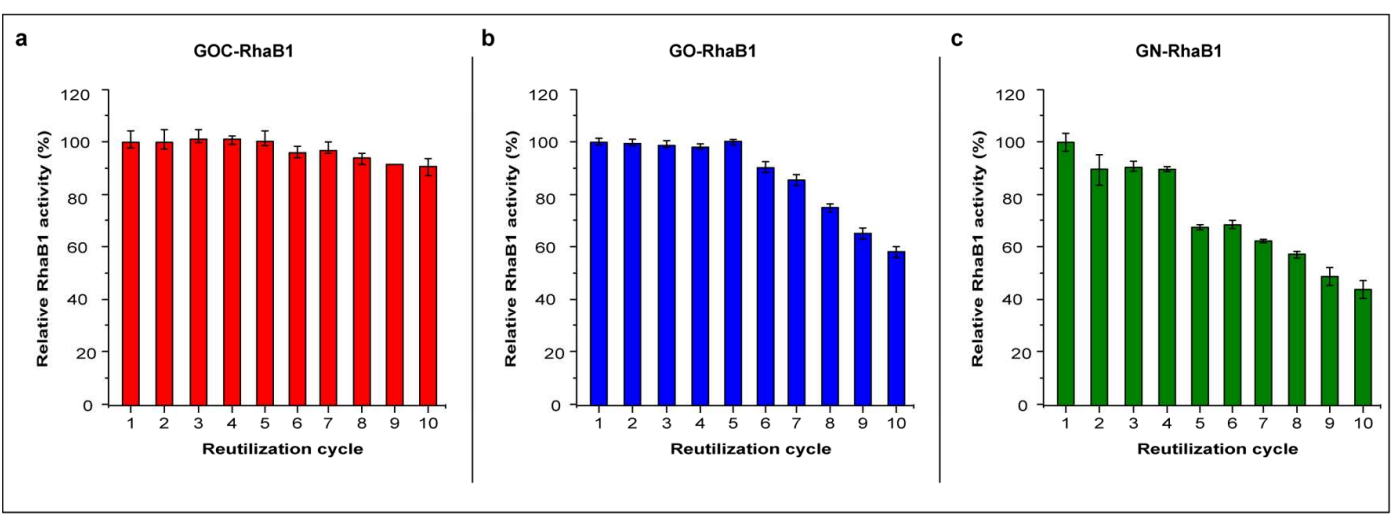

Figure 8. Reusability of GOC-RhaB1 (a), GO-RhaB1 (b), and GN-RhaB1 (c). The error bars are means of two technical replicates, measured in two different samples.

Finally, the possible enzyme leaching from the different nanomaterials was also investigated in the $600 \mu \mathrm{g} / \mathrm{mL}$ RhaB1 immobilization reactions. The rhamnosidase activity of biocomposites that were stored for 10 months at $4^{\circ} \mathrm{C}$ was measured, in both the nanomaterial and the storage buffer. Interestingly, the enzyme leaching was very low in all cases. GOC-RhaB1 was the more remarkable case, as the biocomposite conserved $99.5 \%$ of the enzyme activity, while GORhaB1 and GN-RhaB1 conserved around $95 \%$. Overall, the storage, reusability and leaching results indicate that GOC-RhaB1 is the more robust biocomposite, yielding very good results in terms of stability.

\section{Conclusion}

The comparative analysis of distinct commercial graphene derivatives used as immobilization supports has unveiled their ability to modulate the catalytic properties and stability of a particular enzyme. It is remarkable how differently GO and GOC, which showed to have very similar spectroscopic properties but different morphology, affected the catalytic properties and stability of the alpha-L-rhamnosidase RhaB1. Overall, GOC was the best carrier for RhaB1, since it performed better in enzyme loading capacity, in maintaining the enzyme biochemical characteristics, and in keeping its stability during storage and reutilization. This makes the GOCRhaB1 biocomposite a robust alternative to the RhaB1 non-immobilized version. The obtained results show that the enzyme loading, biochemical properties and stability can vary dramatically depending on the material of choice. Therefore, the selection of an optimal enzyme carrier demands for a thorough screening of the available options, and an in depth characterization of the enzyme properties once it has been immobilized.

\section{Associated content}


Dr. Santiago Cuesta-López is currently employed by the International Center for Advanced Materials and Raw Materials of Castilla y Leon (ICAMCYL), Cubillos de Sil, 24492, León, Spain.

Supporting Information includes XPS data, XRD spectra, Raman spectra, AFM scans and CD spectra, obtained from different analyses of GOC, GOC-RhaB1, GO, GO-RhaB1, GN and GNRhaB1.

\section{Conflict of Interest}

The authors declare that they have no conflict of interests.

\section{Acknowledgements}

We would like to thank Dorett I. Odoni for critically reading and commenting on the manuscript and to María Belén Sánchez-Ilárduya for her support on the XPS data analysis. This work has received funding from the European Union's H2020 research and innovation programme under the Marie Skłodowska-Curie grant agreement $N^{\circ}$ 691095, Ministerio de Economía y Competitividad (CTQ2016-75023-C2-1-P, CTQ2015-70371-REDT MetDrugs Network), and Junta de Castilla y Leon-FEDER grants BU076U16, BU079U16 and UBU-11-A.

\section{References}

(1) Cha, C.; Shin, S. R.; Annabi, N.; Dokmeci, M. R.; Khademhosseini, A. Carbon-Based Nanomaterials: Multifunctional Materials for Biomedical Engineering. ACS Nano 2013, 7 (4), 2891-2897.

(2) Scida, K.; Stege, P. W.; Haby, G.; Messina, G. A.; García, C. D. Recent Applications of Carbon-Based Nanomaterials in Analytical Chemistry: Critical Review. Anal. Chim. Acta 2011, 691 (1-2), 6-17.

(3) Zaytseva, O.; Neumann, G. Carbon Nanomaterials: Production, Impact on Plant Development, Agricultural and Environmental Applications. Chem. Biol. Technol. Agric. 2016, $3(1), 17$.

(4) Sui, Z.-Y.; Cui, Y.; Zhu, J.-H.; Han, B.-H. Preparation of Three-Dimensional Graphene Oxide-Polyethylenimine Porous Materials as Dye and Gas Adsorbents. ACS Appl. Mater. Interfaces 2013, 5 (18), 9172-9179.

(5) Novoselov, K. S.; Geim, A. K.; Morozov, S. V.; Jiang, D.; Zhang, Y.; Dubonos, S. V.; Grigorieva, I. V.; Firsov, A. A. Electric Field Effect in Atomically Thin Carbon Films. Science (80-. ). 2004, 306 (5696). 
(6) Radic, S.; Geitner, N. K.; Podila, R.; Käkinen, A.; Chen, P.; Ke, P. C.; Ding, F. Competitive Binding of Natural Amphiphiles with Graphene Derivatives. Sci. Rep. 2013, $3(1), 2273$.

(7) Homaei, A. A.; Sariri, R.; Vianello, F.; Stevanato, R. Enzyme Immobilization: An Update. J. Chem. Biol. 2013, 6 (4), 185-205.

(8) Mohamad, N. R.; Marzuki, N. H. C.; Buang, N. A.; Huyop, F.; Wahab, R. A. An Overview of Technologies for Immobilization of Enzymes and Surface Analysis Techniques for Immobilized Enzymes. Biotechnol. Biotechnol. Equip. 2015, 29 (2), 205-220.

(9) Yao, K.; Tan, P.; Luo, Y.; Feng, L.; Xu, L.; Liu, Z.; Li, Y.; Peng, R. Graphene Oxide Selectively Enhances Thermostability of Trypsin. ACS Appl. Mater. Interfaces 2015, 7 (22), 12270-12277.

(10) Adrio, J. L.; Demain, A. L. Microbial Enzymes: Tools for Biotechnological Processes. Biomolecules 2014, 4 (1), 117-139.

(11) Lima-Ramos, J.; Neto, W.; Woodley, J. M. Engineering of Biocatalysts and Biocatalytic Processes. Top. Catal. 2014, 57 (5), 301-320.

(12) Pavlidis, I. V.; Tsoufis, T.; Enotiadis, A.; Gournis, D.; Stamatis, H. Functionalized MultiWall Carbon Nanotubes for Lipase Immobilization. Adv. Eng. Mater. 2010, 12 (5), B179_ B183.

(13) Pavlidis, I. V.; Vorhaben, T.; Gournis, D.; Papadopoulos, G. K.; Bornscheuer, U. T.; Stamatis, H. Regulation of Catalytic Behaviour of Hydrolases through Interactions with Functionalized Carbon-Based Nanomaterials. J. Nanoparticle Res. 2012, 14 (5), 842.

(14) Kishore, D.; Talat, M.; Srivastava, O. N.; Kayastha, A. M.; Spain, J. Immobilization of $\beta$ Galactosidase onto Functionalized Graphene Nano-Sheets Using Response Surface Methodology and Its Analytical Applications. PLoS One 2012, 7 (7), e40708.

(15) Hermanová, S.; Zarevúcká, M.; Bouša, D.; Pumera, M.; Sofer, Z. Graphene Oxide Immobilized Enzymes Show High Thermal and Solvent Stability. Nanoscale 2015, 7 (13), 5852-5858.

(16) Patila, M.; Kouloumpis, A.; Gournis, D.; Rudolf, P.; Stamatis, H. Laccase-Functionalized Graphene Oxide Assemblies as Efficient Nanobiocatalysts for Oxidation Reactions. Sensors (Switzerland) 2016, 16 (3), 1-14.

(17) Veerapandian, M.; Hunter, R.; Neethirajan, S. Lipoxygenase-Modified Ru-Bpy/graphene Oxide: Electrochemical Biosensor for on-Farm Monitoring of Non-Esterified Fatty Acid. Biosens. Bioelectron. 2016, 78, 253-258.

(18) Patel, S. K. S.; Choi, S. H.; Kang, Y. C.; Lee, J.-K. Eco-Friendly Composite of $\mathrm{Fe}_{3} \mathrm{O}_{4}$ Reduced Graphene Oxide Particles for Efficient Enzyme Immobilization. ACS Appl. 
Mater. Interfaces 2017, 9 (3), 2213-2222.

(19) Busto, M. D.; Meza, V.; Ortega, N.; Perez-Mateos, M. Immobilization of Naringinase from Aspergillus Niger CECT 2088 in Poly(vinyl Alcohol) Cryogels for the Debittering of Juices. Food Chem. 2007, 104 (3), 1177-1182.

(20) Mueller, M.; Zartl, B.; Schleritzko, A.; Stenzl, M.; Viernstein, H.; Unger, F. M. Rhamnosidase Activity of Selected Probiotics and Their Ability to Hydrolyse Flavonoid Rhamnoglucosides. Bioprocess Biosyst. Eng. 2018, 41 (2), 221-228.

(21) Oguntoyinbo, F. A.; Narbad, A. Multifunctional Properties of Lactobacillus Plantarum Strains Isolated from Fermented Cereal Foods. J. Funct. Foods 2015, 17, 621-631.

(22) Pereira-Caro, G.; Fernández-Quirós, B.; Ludwig, I. A.; Pradas, I.; Crozier, A.; MorenoRojas, J. M. Catabolism of Citrus Flavanones by the Probiotics Bifidobacterium Longum and Lactobacillus Rhamnosus. Eur. J. Nutr. 2018, 57 (1), 231-242.

(23) Nunes, M. A. P.; Vila-Real, H.; Fernandes, P. C. B.; Ribeiro, M. H. L. Immobilization of Naringinase in PVA-Alginate Matrix Using an Innovative Technique. Appl. Biochem. Biotechnol. 2010, 160 (7), 2129-2147.

(24) Puri, M.; Kaur, A.; Singh, R. S.; Schwarz, W. H.; Kaur, A. One-Step Purification and Immobilization of His-Tagged Rhamnosidase for Naringin Hydrolysis. Process Biochem. 2010, 45 (4), 451-456.

(25) Ribeiro, M. H. L.; Rabaça, M. Cross-Linked Enzyme Aggregates of Naringinase: Novel Biocatalysts for Naringin Hydrolysis. Enzyme Res. 2011, 2011, 851272.

(26) Rebroš, M.; Pilniková, A.; ŠImčíková, D.; Weignerová, L.; Stloukal, R.; Křen, V.;

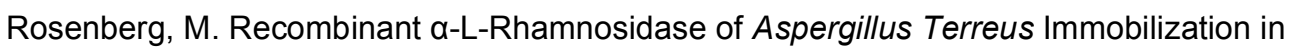
Polyvinylalcohol Hydrogel and Its Application in Rutin Derhamnosylation. Biocatal. Biotransformation 2013, 31 (6), 329-334.

(27) Jesionowski, T.; Zdarta, J.; Krajewska, B. Enzyme Immobilization by Adsorption: A Review. Adsorption 2014, 20 (5-6), 801-821.

(28) Hernandez, K.; Fernandez-Lafuente, R. Control of Protein Immobilization: Coupling Immobilization and Site-Directed Mutagenesis to Improve Biocatalyst or Biosensor Performance. Enzyme Microb. Technol. 2011, 48 (2), 107-122.

(29) Hwang, E. T.; Gu, M. B. Enzyme Stabilization by Nano/microsized Hybrid Materials. Eng. Life Sci. 2013, 13 (1), 49-61.

(30) Srivastava, G.; Singh, K.; Talat, M.; Srivastava, O. N.; Kayastha, A. M. Functionalized Graphene Sheets as Immobilization Matrix for Fenugreek ??-Amylase: Enzyme Kinetics and Stability Studies. PLoS One 2014, 9 (11). 
(31) Zhang, J.; Zhang, J.; Zhang, F.; Yang, H.; Huang, X.; Liu, H.; Guo, S. Graphene Oxide as a Matrix for Enzyme Immobilization. Langmuir 2010, 26 (9), 6083-6085.

(32) Xu, H.; Xie, L.; Wu, D.; Hakkarainen, M. Immobilized Graphene Oxide Nanosheets as Thin but Strong Nanointerfaces in Biocomposites. ACS Sustain. Chem. Eng. 2016, 4 (4), 2211-2222.

(33) Upadhyay, R.; Naskar, S.; Bhaskar, N.; Bose, S.; Basu, B. Modulation of Protein Adsorption and Cell Proliferation on Polyethylene Immobilized Graphene Oxide Reinforced HDPE Bionanocomposites. ACS Appl. Mater. Interfaces 2016, 8 (19), 11954-11968.

(34) Bolibok, P.; Wiśniewski, M.; Roszek, K.; Terzyk, A. P. Controlling Enzymatic Activity by Immobilization on Graphene Oxide. Naturwissenschaften 2017, 104 (3-4), 36.

(35) Moon, I. K.; Lee, J.; Ruoff, R. S.; Lee, H. Reduced Graphene Oxide by Chemical Graphitization. Nat. Commun. 2010, 1 (6), 1-6.

(36) Kellici, S.; Acord, J.; Ball, J.; Reehal, H. S.; Morgan, D.; Saha, B.; Vangsness, M.; Sun, Y.; Bunker, C. E.; Darr, J. A.; Parkin, I.; Evans, J. R. G.; Darr, J. A. A Single Rapid Route for the Synthesis of Reduced Graphene Oxide with Antibacterial Activities. RSC Adv. 2014, 4 (29), 14858.

(37) Khan, M.; Al-Marri, A. H.; Khan, M.; Mohri, N.; Adil, S. F.; Al-Warthan, A.; Siddiqui, M. R. H.; Alkhathlan, H. Z.; Berger, R.; Tremel, W.; Tahir, M. N. Pulicaria Glutinosa Plant Extract: A Green and Eco-Friendly Reducing Agent for the Preparation of Highly Reduced Graphene Oxide. RSC Adv. 2014, 4 (46), 24119-24125.

(38) Chu, X.; Zhu, Q.; Dai, W.-L.; Fan, K. Excellent Catalytic Performance of Graphite Oxide in the Selective Oxidation of Glutaraldehyde by Aqueous Hydrogen Peroxide. RSC Adv. 2012, 2 (18), 7135.

(39) Trusovas, R.; Račiukaitis, G.; Niaura, G.; Barkauskas, J.; Valušis, G.; Pauliukaite, R. Recent Advances in Laser Utilization in the Chemical Modification of Graphene Oxide and Its Applications. Adv. Opt. Mater. 2016, 4 (1), 37-65.

(40) Pretsch, E.; Clerc, T.; Seibl, J.; Simon, W. Tabellen Zur Strukturaufklärung Organischer Verbindungen Mit Spektroskopischen Methoden; Anleitungen für die chemische Laboratoriumspraxis; Springer Berlin Heidelberg: Berlin, Heidelberg, 1976; Vol. 15.

(41) Ramesha, G. K.; Sampath, S. Electrochemical Reduction of Oriented Graphene Oxide Films: An in Situ Raman Spectroelectrochemical Study. J. Phys. Chem. C 2009, 113 (19), 7985-7989.

(42) Dresselhaus, M. S.; Jorio, A.; Saito, R. Characterizing Graphene, Graphite, and Carbon Nanotubes by Raman Spectroscopy. Annu. Rev. Condens. Matter Phys. 2010, 1 (1), 89- 
108.

(43) Hao, Y.; Wang, Y.; Wang, L.; Ni, Z.; Wang, Z.; Wang, R.; Koo, C. K.; Shen, Z.; Thong, J. T. L. Probing Layer Number and Stacking Order of Few-Layer Graphene by Raman Spectroscopy. Small 2010, 6 (2), 195-200.

(44) Xu, Z.; Gao, C. Aqueous Liquid Crystals of Graphene Oxide. ACS Nano 2011, 5 (4), 2908-2915.

(45) Gurunathan, S.; Woong Han, J.; Eppakayala, V.; Kim, J. Green Synthesis of Graphene and Its Cytotoxic Effects in Human Breast Cancer Cells. Int. J. Nanomedicine 2013, 8, 1015.

(46) Gambhir, S.; Jalili, R.; Officer, D. L.; Wallace, G. G. Chemically Converted Graphene: Scalable Chemistries to Enable Processing and Fabrication. NPG Asia Mater. 2015, 7 (6), e186.

(47) Beekwilder, J.; Marcozzi, D.; Vecchi, S.; de Vos, R.; Janssen, P.; Francke, C.; van Hylckama Vlieg, J.; Hall, R. D. Characterization of Rhamnosidases from Lactobacillus Plantarum and Lactobacillus Acidophilus. Appl. Environ. Microbiol. 2009, 75 (11), 34473454.

(48) Avila, M.; Jaquet, M.; Moine, D.; Requena, T.; Pelaez, C.; Arigoni, F.; Jankovic, I. Physiological and Biochemical Characterization of the Two -L-Rhamnosidases of Lactobacillus Plantarum NCC245. Microbiology 2009, 155 (8), 2739-2749.

(49) Ribeiro, M. H. Naringinases: Occurrence, Characteristics, and Applications. Appl. Microbiol. Biotechnol. 2011, 90 (6), 1883-1895.

(50) Singh, K.; Srivastava, G.; Talat, M.; Srivastava, O. N.; Kayastha, A. M. ??-Amylase Immobilization onto Functionalized Graphene Nanosheets as Scaffolds: Its Characterization, Kinetics and Potential Applications in Starch Based Industries. Biochem. Biophys. Reports 2015, 3, 18-25.

(51) Amirbandeh, M.; Taheri-Kafrani, A. Immobilization of Glucoamylase on TriazineFunctionalized Fe 3 O 4 /graphene Oxide Nanocomposite: Improved Stability and Reusability. Int. J. Biol. Macromol. 2016, 93 (Pt A), 1183-1191.

(52) Royvaran, M.; Taheri-Kafrani, A.; Landarani Isfahani, A.; Mohammadi, S. Functionalized Superparamagnetic Graphene Oxide Nanosheet in Enzyme Engineering: A Highly Dispersive, Stable and Robust Biocatalyst. Chem. Eng. J. 2016, 288, 414-422.

(53) Wang, M.; Gao, B.; Tang, D.; Sun, H.; Yin, X.; Yu, C. Effects of Temperature on Aggregation Kinetics of Graphene Oxide in Aqueous Solutions. Colloids Surfaces $A$ Physicochem. Eng. Asp. 2018, 538, 63-72.

(54) Pelton, J. T.; McLean, L. R. Spectroscopic Methods for Analysis of Protein Secondary 
Structure. Anal. Biochem. 2000, 277 (2), 167-176.

(55) Goldberg, M. E.; Chaffotte, A. F. Undistorted Structural Analysis of Soluble Proteins by Attenuated Total Reflectance Infrared Spectroscopy. Protein Sci. 2005, 14 (11), 27812792.

(56) Seabourn, B. W.; Chung, O. K.; Seib, P. A.; Mathewson, P. R. Determination of Secondary Structural Changes in Gluten Proteins during Mixing Using Fourier Transform Horizontal Attenuated Total Reflectance Spectroscopy. J. Agric. Food Chem. 2008, 56 (11), 4236-4243.

(57) Shai, Y. ATR-FTIR Studies in Pore Forming and Membrane Induced Fusion Peptides. Biochim. Biophys. Acta - Biomembr. 2013, 1828 (10), 2306-2313.

(58) Hammaecher, C.; Joris, B.; Goormaghtigh, E.; Marchand-Brynaert, J. Photoactivable Nonsymmetrical Bifunctional Linkers for Protein Immobilization on Attenuated Total Reflectance FTIR Optical Devices. European J. Org. Chem. 2013, 2013 (35), 79527959.

(59) Han, Y.; Li, K.; Chen, H.; Li, J. Properties of Soy Protein Isolate Biopolymer Film Modified by Graphene. Polymers (Basel). 2017, 9 (12), 312.

(60) Hernández-Cancel, G.; Suazo-Dávila, D.; Ojeda-Cruzado, A. J.; García-Torres, D.; Cabrera, C. R.; Griebenow, K. Graphene Oxide as a Protein Matrix: Influence on Protein Biophysical Properties. J. Nanobiotechnology 2015, 13 (1), 70.

(61) Soria, F.; Ellenrieder, G.; Oliveira, G. B.; Cabrera, M.; Carvalho, L. B. $\alpha$-L-Rhamnosidase of Aspergillus Terreus Immobilized on Ferromagnetic Supports. Appl. Microbiol.

Biotechnol. 2012, 93 (3), 1127-1134.

(62) Li, Y.; Wang, X. Y.; Jiang, X. P.; Ye, J. J.; Zhang, Y. W.; Zhang, X. Y. Fabrication of Graphene Oxide Decorated with Fe3O4@SiO2 for Immobilization of Cellulase. J. Nanoparticle Res. 2015, 17 (1).

(63) Singh, N.; Srivastava, G.; Talat, M.; Raghubanshi, H.; Srivastava, O. N.; Kayastha, A. M. Cicer a-Galactosidase Immobilization onto Functionalized Graphene Nanosheets Using Response Surface Method and Its Applications. Food Chem. 2014, 142, 430-438.

(64) Rosenberg, I. M. Protein Analysis and Purification : Benchtop Techniques; Birkhäuser, 2005.

(65) Li, L.; Yu, Y.; Zhang, X.; Jiang, Z.; Zhu, Y.; Xiao, A.; Ni, H.; Chen, F. Expression and Biochemical Characterization of Recombinant $\alpha-L-R h a m n o s i d a s e ~ R-R h a 1$ from Aspergillus Niger JMU-TS528. Int. J. Biol. Macromol. 2016, 85, 391-399.

(66) Yadav, S.; Yadav, V.; Yadav, S.; Yadav, K. D. S. Purification, Characterisation and Application of a-L-Rhamnosidase from Penicillium Citrinum MTCC-8897. Int. J. Food Sci. 
Technol. 2012, 47 (2), 290-298.

(67) Alvarenga, A. E.; Romero, C. M.; Castro, G. R. A Novel a-L-Rhamnosidase with Potential Applications in Citrus Juice Industry and in Winemaking. Eur. Food Res. Technol. 2013, 237 (6), 977-985.

(68) Yadav, V.; Yadav, S.; Yadava, S.; Yadav, K. D. S. a-L-Rhamnosidase from Aspergillus Flavus MTCC-9606 Isolated from Lemon Fruit Peel. Int. J. Food Sci. Technol. 2011, 46 (2), 350-357.

(69) YANAI, T.; SATO, M. Purification and Characterization of an $\alpha-L$-Rhamnosidase from Pichia Angusta X349. Biosci. Biotechnol. Biochem. 2000, 64 (10), 2179-2185.

(70) Pahujani, S.; Kanwar, S. S.; Chauhan, G.; Gupta, R. Glutaraldehyde Activation of Polymer Nylon-6 for Lipase Immobilization: Enzyme Characteristics and Stability. Bioresour. Technol. 2008, 99 (7), 2566-2570.

(71) Patel, S. K. S.; Otari, S. V.; Li, J.; Kim, D. R.; Kim, S. C.; Cho, B.-K.; Kalia, V. C.; Kang, Y. C.; Lee, J.-K. Synthesis of Cross-Linked Protein-Metal Hybrid Nanoflowers and Its Application in Repeated Batch Decolorization of Synthetic Dyes. J. Hazard. Mater. 2018, $347,442-450$.

(72) Garcia-Galan, C.; Barbosa, O.; Fernandez-Lafuente, R. Stabilization of the Hexameric Glutamate Dehydrogenase from Escherichia Coli by Cations and Polyethyleneimine. Enzyme Microb. Technol. 2013, 52 (4-5), 211-217.

(73) Schön, A.; Clarkson, B. R.; Siles, R.; Ross, P.; Brown, R. K.; Freire, E. Denatured State Aggregation Parameters Derived from Concentration Dependence of Protein Stability. Anal. Biochem. 2015, 488, 45-50.

(74) Lin, L.-L.; Chi, M.-C.; Lan, Y.-J.; Lin, M.-G.; Juang, T.-Y.; Wang, T.-F. Facile Immobilization of Bacillus Licheniformis $\gamma$-Glutamyltranspeptidase onto Graphene Oxide Nanosheets and Its Application to the Biocatalytic Synthesis of $\mathrm{Y}$ - L -Glutamyl Peptides. Int. J. Biol. Macromol. 2017. 
2

3

4

5

6

7

8

9

Table of contents graphic

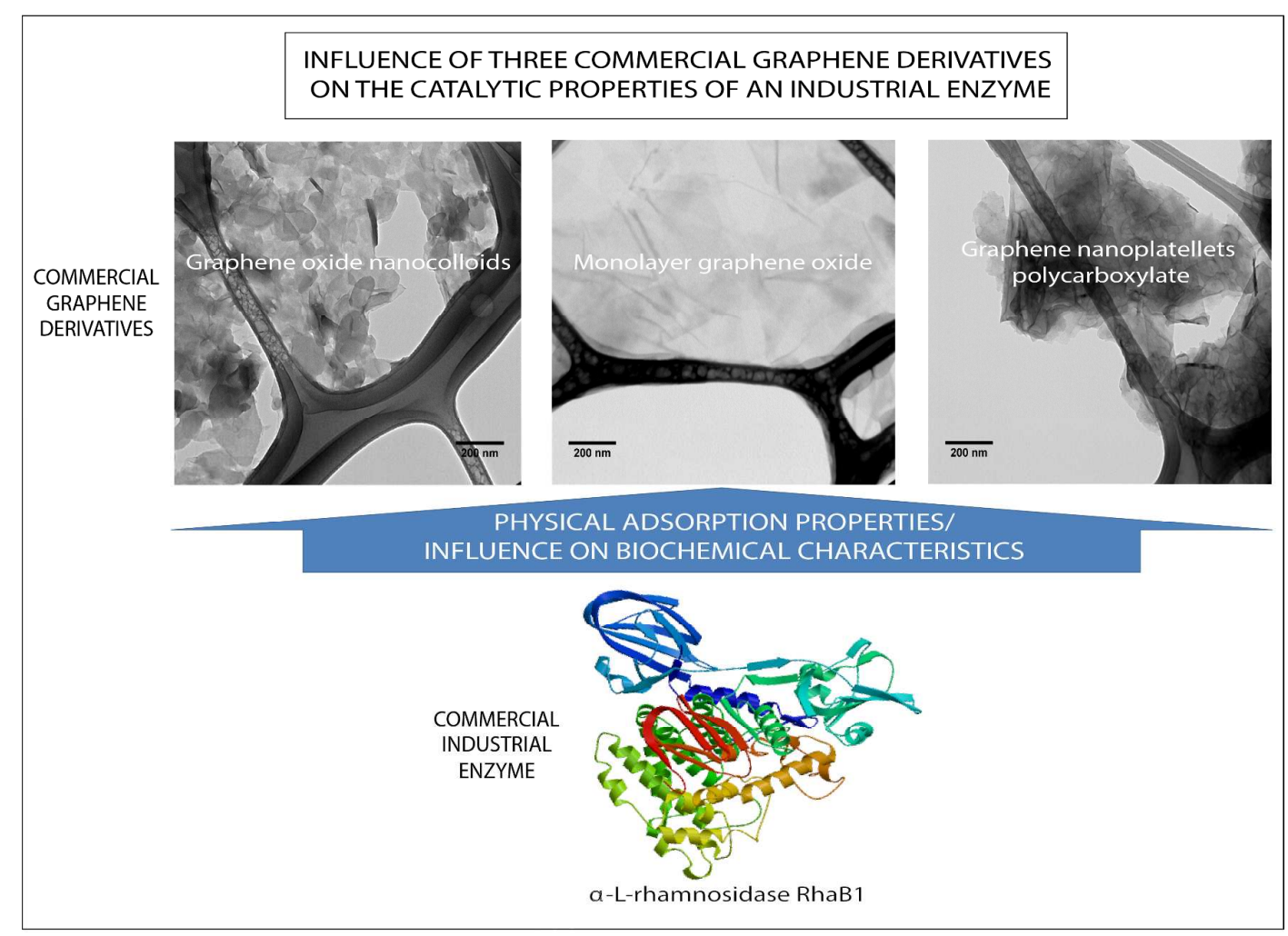

